\title{
The Presumption of Innocence, Reflections on Two Philosophical-Analytical Formulations
}

Lola Shehu

\begin{abstract}
"Better ten free guilty than an innocent convict," proclaimed by French jurists from the thirteenth century until the time of the revolution, was gradually shadowed by another principle, less favorable to the defendant than found spread at that time "Blaming harms innocence." Although the law obliged judges to question the arrested person within twenty-four hours, the long-term imprisonment of the suspects became very common. As a consequence for these persons it was thought that they were guilty of violating the important principle in this way. Understanding and applying this principle in practice is the main guarantee that defendants' rights are protected throughout the trial phases. The dual nature of the presumption of innocence, as an individual right and a simultaneous state obligation exaggerating the prospect, which proposes a constitutional basis of the rule of law. Some authors indifferently use the terms "presumption of innocence" or "presumption of non-guilty" to identify the same concept without attributing different shadow formulas to specific meanings. Others, however, associate the "presumption of innocence" formula with the authentic and clear expression of the principle, while the term "presumption of non-guilty" indicates the dictated constitutional regulator by questioning the breadth, purpose and therefore the choice of this term.
\end{abstract}

Keywords: principle, presumption of innocence, defendant, denunciation, "not guilty" etc. 